\title{
Optimal operation of a multipurpose multireservoir system in the Eastern Nile River Basin
}

\author{
Q. Goor ${ }^{1}$, C. Halleux ${ }^{1}$, Y. Mohamed ${ }^{2,3}$, and A. Tilmant ${ }^{4}$ \\ ${ }^{1}$ Earth and Life Institute, Environmental Sciences, Université catholique de Louvain, Louvain-la-Neuve, Belgium \\ ${ }^{2}$ Department of Management and Institutions, UNESCO-IHE, Delft, The Netherlands \\ ${ }^{3}$ Department of Water Resources, Delft University of Technology, Delft, The Netherlands \\ ${ }^{4}$ Institute of Environmental Engineering, Swiss Federal Institute of Technology, Zurich, Switzerland
}

Received: 10 June 2010 - Published in Hydrol. Earth Syst. Sci. Discuss.: 6 July 2010

Revised: 14 September 2010 - Accepted: 6 October 2010 - Published: 12 October 2010

\begin{abstract}
The upper Blue Nile River Basin in Ethiopia is a largely untapped resource despite its huge potential for hydropower generation and irrigated agriculture. Controversies exist as to whether the numerous infrastructural development projects that are on the drawing board in Ethiopia will generate positive or negative externalities downstream in Sudan and Egypt. This study attempts at (1) examining the (re-)operation of infrastructures, in particular the proposed reservoirs in Ethiopia and the High Aswan Dam and (2) assessing the economic benefits and costs associated with the storage infrastructures in Ethiopia and their spatial and temporal distribution. To achieve this, a basin-wide integrated hydro-economic model has been developed. The model integrates essential hydrologic, economic and institutional components of the river basin in order to explore both the hydrologic and economic consequences of various policy options and planned infrastructural projects. Unlike most of the deterministic economic-hydrologic models reported in the literature, a stochastic programming formulation has been adopted in order to: (i) understand the effect of the hydrologic uncertainty on management decisions, (ii) determine allocation policies that naturally hedge against the hydrological risk, and (iii) assess the relevant risk indicators. The study reveals that the development of four mega dams in the upper part of the Blue Nile Basin would change the drawdown refill cycle of the High Aswan Dam. Should the operation of the reservoirs be coordinated, they would enable an average annual saving of at least 2.5 billion $\mathrm{m}^{3}$ through reduced evaporation losses from the Lake Nasser. Moreover, the new reservoirs (Karadobi, Beko-Abo, Mandaya and Bor-
\end{abstract}

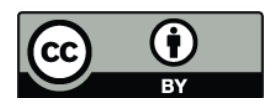

Correspondence to: A. Tilmant (amaury.tilmant@me.com) der) in Ethiopia would have significant positive impacts on hydropower generation and irrigation in Ethiopia and Sudan: at the basin scale, the annual energy generation is boosted by 38.5 TWh amongst which 14.2 TWh due to storage. Moreover, the regulation capacity of the above mentioned reservoirs would enable an increase of the Sudanese irrigated area by $5.5 \%$.

\section{Introduction}

The Nile River Basin covers an area representing one tenth of Africa (about 3 million $\mathrm{km}^{2}$ ) and is shared by ten countries. The river is characterized by a considerable seasonal and inter-annual variability that challenges the management of the water resources. In the top of that, the water resources availability and uses are unevenly distributed amongst the countries: Egypt and Sudan are the largest water consumers while this is negligible for Ethiopia, even though $85 \%$ of the Nile waters comes from Ethiopian highlands. To meet the growing demand for food and energy, the Nile riparian countries will further develop their water resources. For example, in the Blue Nile River Basin, between Lake Tana in Ethiopia and Karthoum in Sudan, large reservoirs, hydropower stations and irrigation areas are being planned with the ultimate goal of boosting the production of cheap hydroelectricity and increasing food security (Guariso and Whittington, 1987; Block, 2007; Block and Strzepek, 2010; Georgakakos, 2006; Nile Basin Initiative, May 2010a). Due to the fugitive nature of water, those developments will generate both positive and negative externalities downstream and must therefore be carefully planned, ideally in a cooperative way with downstream riparians. This is precisely the raison d'etre of

Published by Copernicus Publications on behalf of the European Geosciences Union. 
the Nile Basin Initiative (and the associated two Subsidiary Action programmes, SAPs), an international institution expected to provide a framework for basin-wide cooperation including the identification and implementation of new infrastructural projects (Nile Basin Initiative, May 2010b).

Assessing the positive and negative externalities of infrastructural projects calls for integrated basin-wide modelling studies. Integrated basin-wide models are typically built around arcs and nodes: the former may represent natural inflows to the system, canals, the river network, whereas the nodes are used to represent confluences, reservoirs, abstraction points, demand sites, etc. (Harou et al., 2009). Ringler et al. (2004) analyze the optimal flow allocation in the Mekong River Basin using an integrated economichydrologic model. In a series of papers, Ward and Michelsen (2002); Ward et al. (2006) investigate the hydrologic and economic impacts of various policy options in the Rio Grande Basin using a hydro-economic model. In Whittington et al. (2005), a deterministic hydro-economic model was developed for the entire Nile River Basin and several development scenarios were analyzed. Their study revealed, amongst other things, that the annual benefits of cooperation between the Nile countries can be as high as 4.9 billion US\$/y. In Georgakakos (2006), a DSS is developed for the Nile River Basin: the model can simulate the Nile response to different hydrological scenarios and provide reservoir operating strategies for real-time control through the Extended Linear Quadratic Gaussian (ELQG) optimization algorithm. Recently, Block and Strzepek (2010) analyzed the transient conditions associated with the period of filling some of the proposed dams in Ethiopia, under climate change scenarios.

In this study, unlike most of the deterministic economichydrologic models reported in the literature, a stochastic programming formulation has been adopted for mid- to longterm water resources planning and management of the Nile River Basin. The objectives of the study presented in this paper is to assesses (1) the (re-)operation of the largest hydraulic infrastructures, in particular the proposed reservoirs in Ethiopia and the High Aswan Dam and (2) the economic benefits and costs associated with new storages in Ethiopia.

The paper begins with a description of the methodology. The next section describes the Eastern Nile hydro-system, including relevant data inputs and parameters of the basin-wide allocation model. Simulation results and their implications are presented, analyzed and discussed in the next section. Finally, conclusions and perspectives for future research are given in Sect. 5.

\section{Methodology}

\subsection{Introduction}

Optimal coordinated operation of reservoir systems is expected to yield larger benefits than independently operating projects (Labadie, 2004). Until recently, huge simplifications and approximations were required to get optimization results for hydro-systems involving more than 3 to 4 reservoirs, while considering stochastic variables. However recent advances in mathematical programming have reduced this computational burden. The new algorithms can also better handle the hydrological uncertainty, which is inherent to the operation of a multireservoir system. One of these algorithm is Stochastic Dual Dynamic Programming (SDDP).

\subsection{Stochastic dual dynamic programming}

In this study, the basin-wide allocation model relies on SDDP, an algorithm that can solve large-scale stochastic optimization problems. The model determines economically efficient allocation policies, including reservoir releases, and then simulates the system operation for various hydrological scenarios. The main challenge of optimal mid- to longterm reservoir operation is to consider the stochasticity of future inflows. Optimal reservoir operation can be seen as a stochastic multi-stage decision making problem that can be solved using the recursive Stochastic Dynamic Programming (SDP) equation, which maximize, at each stage $t$, the sum of immediate $f_{t}(\cdot)$ and expected future $F_{t+1}$ benefits from the system operation:

$$
F_{t}\left(\boldsymbol{X}_{t}\right)=\max _{\boldsymbol{R}_{t}}\left\{f_{t}\left(\boldsymbol{X}_{t}, \boldsymbol{R}_{t}\right)+\underset{\boldsymbol{h}_{t+1} \mid \boldsymbol{h}_{t}}{E}\left[F_{t+1}\left(\boldsymbol{X}_{t+1}\right)\right]\right\}
$$

where $\boldsymbol{X}_{t}$ is a vector of state variables, which typically include $\boldsymbol{s}_{t}$, the volume of water stored in the system at the beginning of period $t$ and information about current or forecasted inflows to the system $\boldsymbol{h}_{t} . \boldsymbol{R}_{\mathrm{t}}$ is the vector of decision variables and $E[\cdot]$ is the expectation operator to observe hydrologic condition $\boldsymbol{h}_{t+1}$ given the state $\boldsymbol{h}_{t}$ (Huang et al., 1991; Tejada-Guibert et al., 1995).

Traditional approaches to solve the above-mentioned problem relies on the discretization of the state-space domain and the evaluation of $F_{t+1}$ at each grid points. This methodology usually fails in the context of multireservoir systems because it requires to explore every feasible combinations of the state variables. As a consequence, the computational effort required to solve the problem increases exponentially with the number of reservoirs (curse of dimensionality of SDP).

Stochastic Dual Dynamic Programming is one of the few algorithms available to solve multipurpose multireservoir operation problems in a stochastic environment. The methodology belongs to the field of approximate dynamic programming (Powell, 2007) and relies on an analytical representation of the benefit-to-go function $F_{t+1}$. This is achieved by approximating $F_{t+1}$ by piecewise linear segments: the statespace domain is sampled and a linear approximation of $F_{t+1}$ (cut) is calculated at each sampled point. SDDP uses a cyclic optimization/simulation strategy to increase the accuracy of 
the solution by adding new cuts through a Benders decomposition scheme (Pereira and Pinto, 1985). $F_{t+1}$ is thus a scalar, stored as a set of constraints representing the linear segments. The parameters of the linear segments, which provide an "outer" approximation of $F_{t+1}$, can be calculated from the primal and the dual information available at the optimal solution of the one-stage optimization problem. A comprehensive and recent description of the algorithm can be found in Tilmant and Kelman (2007) and Tilmant et al. (2008).

The SDDP formulation adopted in this study considers a dynamic allocation of water resources between hydropower and irrigation (Tilmant et al., 2009). In this approach, water resources are allocated to its most productive use throughout the entire river basin. The model seeks to maximize the aggregated net benefits from both the irrigation and hydropower sectors by identifying optimal release $r_{t}(j)$ and irrigation withdrawal $i_{t}(j)$ decisions at each node $j$ and for each time $t \in[1 \ldots T]$ where $T$ is the length of the planning period. The immediate benefit function $f_{t}(\cdot)$ can include up to three terms: (1) the net benefits from energy generation, (2) the net benefits from irrigated agriculture (only observed at the end of the irrigation season, which is specific for each crop), and (3) penalties for not meeting operational, physical, institutional and/or legal constraints such as minimum flows, minimum storage volumes, minimum water withdrawals, etc.

Assuming that the system consists of $J$ hydropower plants, immediate short-run net benefits from hydropower generation can be written as:

$\mathrm{HP}_{t}=\tau_{t} \sum_{j=1}^{J}\left(\pi_{t}^{h}(j)-\theta^{h}(j)\right) \alpha(j) \hat{P}_{t}(j)$

where $\tau$ is the number of hours in period $t, \hat{P}_{t}(j)$ (MW) the power generated by hydropower plant $j$ during period $t, \pi^{h}(j)$ is the short-run marginal cost (SRMC) of the hydrothermal electrical system to which power plant $j$ contributes (US\$/MWh), $\theta^{h}(j)$ is the O\&M cost of hydropower plant $j$ (US\$/MWh) and $\alpha$ is an adjustment coefficient (-). Note that the function (2) is non-convex (the production of hydroelectricity depends on the product of the storage (head) and release terms). Consequently, the efficient Benders decomposition scheme cannot be applied. To remove this source of non-convexity, the hydropower production function is estimated by a convex hull approximation. The detailed methodology to calculate the convex hull approximation and the parameters is described by Goor et al. (2010).

The net benefit from the agricultural sector, denoted $\mathrm{IR}_{t}$, is the sum of the benefits obtained at each irrigation demand site $d$ as a function of the volume of water $y_{t_{f}}^{(d, p)}$ that has been delivered to the crops $p$ at that site $d$ during the irrigation season:

$$
\operatorname{IR}_{t}= \begin{cases}\sum_{d, p} \hat{f}_{t_{f}}^{i,(d, p)}\left(y_{t_{f}}^{(d, p)}\right) & \text { if } t=t_{f} \\ 0 & \text { if } t \neq t_{f}\end{cases}
$$

Benefits from the irrigated agricultural sector $\mathrm{IR}_{t}$ are introduced in the objective function by considering "dummy" reservoirs of accumulated water devoted to irrigation, which are being refilled throughout the irrigation season and depleted at the end of that season (stage $t_{f}$ ). Net benefits from agricultural water use is therefore accounted for only when crops are harvested. To achieve this, an additional state variable $\boldsymbol{y}_{t}$, representing the beginning-of-period accumulated water into those "dummy" reservoirs must be added to the state vector $\boldsymbol{X}_{t}$. Moreover, at each demand site $d$, the model can handle various types of crops $p$, with its own benefit function $\hat{f}^{i,(p, d)}$. Assuming that the water rationing, when it occurs, is evenly distributed over the irrigation season, the effect of water stress on actual crop yield $c$ is related to the deficit of water supplied throughout the agricultural season by the crop-specific yield response factor $K_{y}(p)(-)$ (Tilmant et al., 2008):

$c(p, d)=\bar{c}(p, d)\left[1-K_{y}(p)\left(1-\frac{y_{t_{f}}^{(p, d)}}{\bar{y}_{t_{f}}^{(p, d)}}\right)\right]$

where $\bar{c}(p, d)$ is the maximum crop yield (T/ha) achieved when the seasonal crop water requirement $\bar{y}_{t_{f}}^{(p, d)}$ is supplied. The short-run net benefits $f^{i,(p, d)}$ of crop $p$, at demand site $d$ is therefore expressed by:

$\hat{f}_{t_{f}}^{i,(p, d)}\left(y_{t_{f}}^{p, d}\right)=\left[\pi^{i}(p, d) c(p, d)-\theta^{i}(p, d)\right] A(p, d)$

where $\pi^{i}(p, d)(\mathrm{US} \$ / \mathrm{T})$ and $\theta^{i}(p, d)$ (US\$/ha) are, respectively the farm gate price and the variable costs of crop $p$, at the given site $d . A(p, d)$ (ha) is the cultivated area.

Considering a dynamic management approach where the objective is to maximize the sum of net benefits from both sectors, the one-stage objective function becomes:

$f_{t}\left(\boldsymbol{s}_{t}, \boldsymbol{q}_{t}, \boldsymbol{r}_{t}, \boldsymbol{y}_{t}\right)=\mathrm{HP}_{t}+\mathrm{IR}_{t}-\xi_{t}^{\prime} \boldsymbol{x}_{t}$

where $\boldsymbol{x}_{t}$ is a vector of slack/surplus variables which are penalized in the objective function by the penalties $\boldsymbol{\xi}_{t}$ (US\$/unit of deficit or surplus).

Assuming that the hydro-system status, represented by the vector of state variables $\boldsymbol{X}_{t}$, includes the beginning-of-period storage $\boldsymbol{s}_{t}$, the hydrological information summarized by the previous period inflows to the system $\boldsymbol{q}_{t-1}$ and the end-ofperiod accumulated water into irrigation "dummy" reservoirs $\boldsymbol{y}_{t+1}$, the one-stage SDDP optimization sub-problem can be written as:

$F_{t}\left(\boldsymbol{s}_{t}, \boldsymbol{q}_{t-1}, \boldsymbol{y}_{t}\right)=\max \left\{f_{t}\left(\boldsymbol{s}_{t}, \boldsymbol{q}_{t}, \boldsymbol{r}_{t}, \boldsymbol{y}_{t}\right)+F_{t+1}\right\}$

Subject to a set of constraints among which the mass conservation for all periods $t$ :

$s_{t+1}-\mathbf{C}^{\mathbf{R}}\left(r_{t}+l_{t}\right)-\mathbf{C}^{\mathbf{I}}\left(i_{t}\right)+e_{t}\left(s_{t}, s_{t+1}\right)=s_{t}+q_{t}$ 


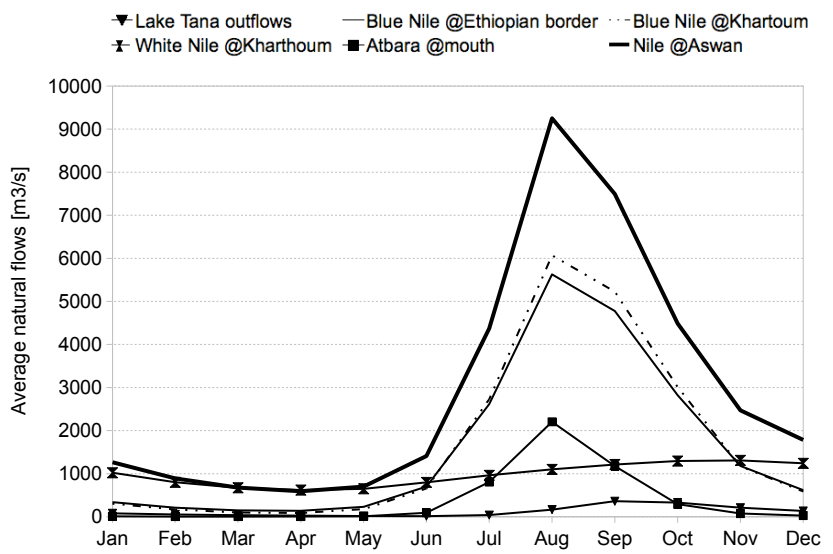

Fig. 1. Naturalized discharge of the Nile at key locations in the Nile Basin (period 1954-2000).

where $\boldsymbol{i}_{t}$ is the vector of water withdrawals for irrigation purposes, $\boldsymbol{l}_{t}$ and $\boldsymbol{e}_{t}$ are the vectors of spillage and evaporation losses, respectively. $\mathbf{C}^{\mathbf{R}}$ is the reservoir system connectivity matrix $\left(\mathbf{C}_{\mathbf{j}, \mathbf{k}}^{\mathbf{R}}=1(-1)\right.$ when reservoir $j$ receives (releases) water from (to) reservoir $k$ ). The irrigation system has its own topology modelled by the connectivity matrix $\mathbf{C}^{\mathbf{I}}$ where irrigation withdrawals and returns flows are connected to the reservoir system: $\mathbf{C}_{\mathbf{j}, \mathbf{i}}^{\mathbf{I}}=\mu$ (percentage of irrigation withdrawals that will drain back to the river) when reservoir $j$ receives return flows from the irrigation site $i$ and/or $\mathbf{C}_{\mathbf{j}, \mathbf{i}}^{\mathbf{I}}=-1$ when water is withdrawn from reservoir $j$ to the irrigation site $i$.

Lower and upper bounds on storage can be assigned to storage levels:

$\underline{\boldsymbol{s}}_{t+1} \leq \boldsymbol{s}_{t+1} \leq \overline{\boldsymbol{s}}_{t+1}$

Limits on reservoir releases are introduced for maximum turbining capacity of the hydropower station, to maintain a desired downstream minimum flow for water quality, navigation, etc.

$\underline{\boldsymbol{r}}_{t} \leqslant \boldsymbol{r}_{t} \leqslant \overline{\boldsymbol{r}}_{t}$

Irrigation water withdrawals can be limited by the pumping station or channel capacity:

$\underline{\boldsymbol{i}}_{t} \leqslant \boldsymbol{i}_{t} \leqslant \overline{\boldsymbol{i}}_{t}$

Throughout the growing season, a continuity equation must ensure the mass balance in the dummy reservoirs of accumulated water for irrigation purposes:

$\boldsymbol{y}_{t+1}-\boldsymbol{\epsilon} \boldsymbol{i}_{t}=\boldsymbol{y}_{t}$

where $\epsilon$ is a vector of irrigation efficiencies. These dummy reservoirs have their own lower and upper bounds:

$\underline{\boldsymbol{y}}_{t+1} \leqslant \boldsymbol{y}_{t+1} \leqslant \overline{\boldsymbol{y}}_{t+1}$
Benefit-to-go function $F_{t+1}$ is stored in the constraints set:

$$
\left\{\begin{array}{l}
F_{t+1}-\varphi_{t+1}^{1} s_{t+1}-\eta_{t+1}^{1} y_{t+1} \leq \gamma_{t+1}^{1} \boldsymbol{q}_{t}+\boldsymbol{\beta}_{t+1}^{1} \\
\vdots \\
F_{t+1}-\varphi_{t+1}^{L} s_{t+1}-\eta_{t+1}^{L} y_{t+1} \leq \gamma_{t+1}^{L} \boldsymbol{q}_{t}+\boldsymbol{\beta}_{t+1}^{L}
\end{array}\right.
$$

where $\boldsymbol{\varphi}_{t+1}^{l}, \boldsymbol{\eta}_{t+1}^{l}, \boldsymbol{\gamma}_{t+1}^{l}$ and $\boldsymbol{\beta}_{t+1}^{l}$ are expected values of the parameters defining the $l^{\text {th }}$ hyperplane. See Tilmant and Kelman (2007) and Goor et al. (2010) for a detailed explanation on how those parameters are derived from the primal and dual information available at the solution of the numerous one-stage optimization problems (7-15) at stage $t+1$. The approximation of hydropower functions $\hat{\boldsymbol{P}}_{t}$ are also stored as constraints:

$$
\left\{\begin{array}{l}
\hat{\boldsymbol{P}}_{t}-\boldsymbol{\psi}^{1} \boldsymbol{s}_{t+1} / 2-\boldsymbol{\omega}^{1} \boldsymbol{r}_{t} \leq \boldsymbol{\delta}^{1}+\boldsymbol{\psi}^{1} \boldsymbol{s}_{t} / 2 \\
\vdots \\
\hat{\boldsymbol{P}}_{t}-\boldsymbol{\psi}^{H} \boldsymbol{s}_{t+1} / 2-\boldsymbol{\omega}^{H} \boldsymbol{r}_{t} \leq \boldsymbol{\delta}^{H}+\boldsymbol{\psi}^{H} \boldsymbol{s}_{t} / 2
\end{array}\right.
$$

where $\hat{\boldsymbol{P}}_{\boldsymbol{t}}$ is the $(J \times 1)$ vector of approximated hydropower generated during period $t, \boldsymbol{\psi}^{h}, \omega^{h}$ and $\delta^{h}$ are $(1 \times J)$ vectors of hyperplanes $h$ parameters. The detailed methodology to calculate the convex hull approximation and the parameters $\psi^{h}, \omega^{h}$ and $\delta^{h}$ is described by Goor et al. (2010).

The SDDP model is coded in MATLAB ${ }^{\circledR}$ and relies on the open-source COIN-OR Linear Programming solver CLP (http://www.coin-or.org/projects/Clp.xml) to solve the onestage problem (7) to (15).

\section{SDDP model for the Eastern Nile River Basin}

\subsection{The Nile River Basin}

The Nile River Basin covers an area of about 3 million $\mathrm{km}^{2}$ and is shared by ten countries (Burundi, Democratic Republic of Congo, Egypt, Eritrea, Ethiopia, Kenya, Rwanda, Sudan, Tanzania, Uganda). The Blue Nile and the White Nile merge at Karthoum, in Sudan, to form the main Nile that discharges into the Mediterranean Sea. The Blue Nile originates from the Lake Tana, in the Highlands of Ethiopia. After flowing into abrupt canyons in Ethiopia, characterized by a temperate climate, it enters the plain in Sudan where the climate is much more arid. Given its equatorial position and associated high precipitations, the discharge of the Blue Nile in Ethiopia grows rapidly as it receives water from the numerous tributaries flowing from the highlands. The flow regime of the Blue Nile is currently largely unregulated and is characterized by a very high seasonal and inter-annual variability (Fig. 1). The White Nile drains an area from the Lake Victoria to Karthoum. After flowing through the Sudd (one of the world's largest wetlands), it receives water from the Baro-Akobo-Sobat sub-basin, flowing from Ethiopia to join Bahr Eljabel at Malakal to form the White Nile. Compared to the Blue Nile, the flow regime of the White Nile exhibits 

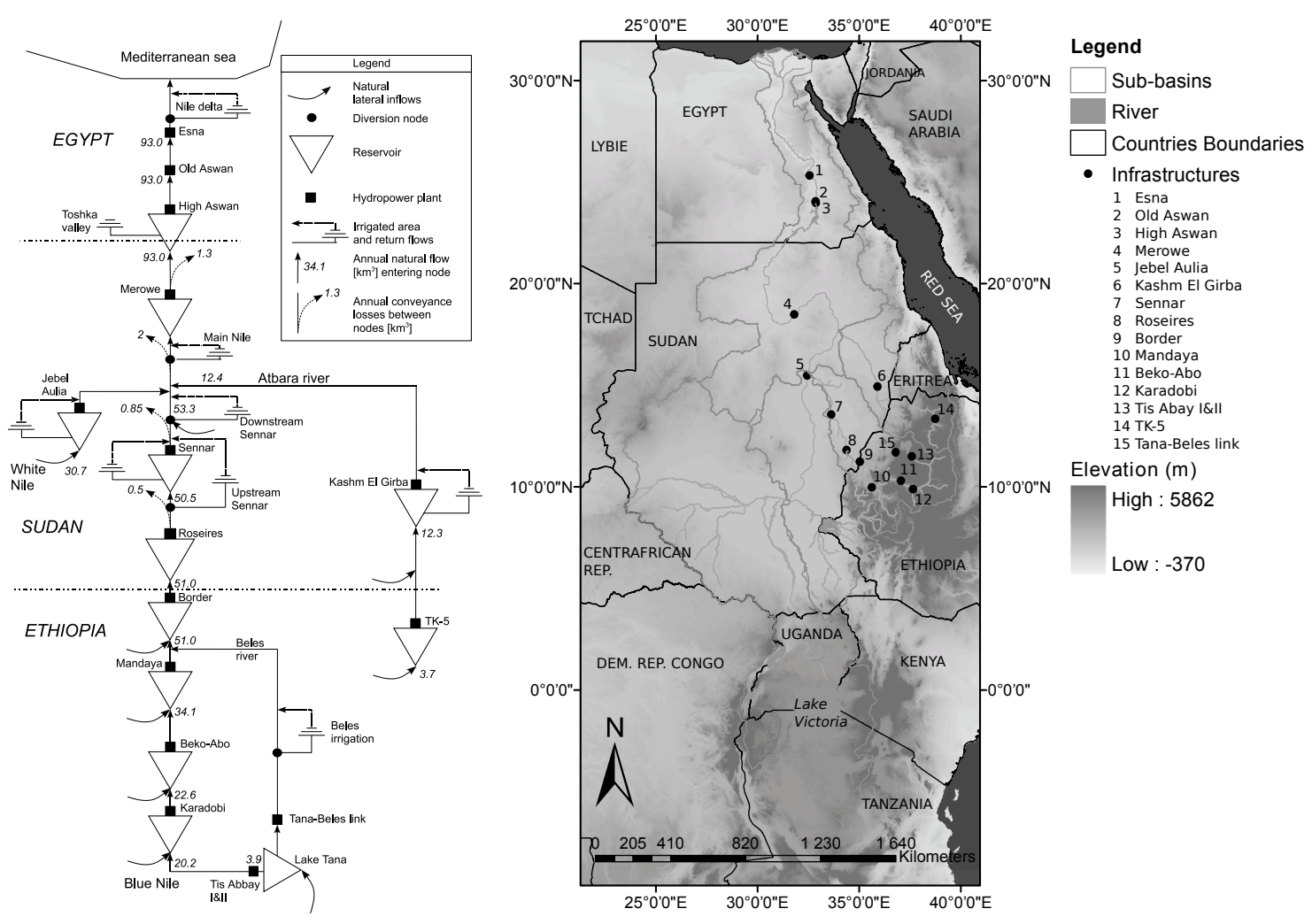

Fig. 2. Topological view of the Eastern Nile River Basin hydro-system.

less seasonality given the natural regulation achieved by the Sudd (Fig. 1). Before entering Egypt, the Main Nile receives water from the Atbara sub-basin, which is its latest significant affluent. The Eastern Nile River Basin is composed of: the Blue Nile, the Atbara, the Baro-Aboko-Sobat, the White Nile downstream Malakal and the Main Nile sub-basins, as illustrated in Fig. 2.

\subsection{Geo-political background}

Egypt, the most downstream country of the basin consumes about $80 \%$ of the Nile waters, while Ethiopia has a negligible consumption, even though $85 \%$ of the Nile waters comes from the Ethiopian Highlands (Wu and Whittington, 2006). To secure its share of the Nile waters, Egypt has signed several agreements with its riparians: Great Britain on behalf of Sudan, Kenya, Tanzania and Uganda and with Sudan in 1959 after its independence. Historically, those agreements were very controversial between upstream (source countries), and downstream countries (Egypt and Sudan). The most important treaty is the 1959 agreement between Egypt and Sudan about the sharing of the Nile waters. It assumes that, given an agreed upon annual average of $84 \mathrm{~km}^{3}\left(1 \mathrm{~km}^{3}=10^{9} \mathrm{~m}^{3}\right)$ of Nile yield, the allotment for Egypt is $55.5 \mathrm{~km}^{3} \mathrm{y}^{-1}$ while Sudan receives $18.5 \mathrm{~km}^{3} \mathrm{y}^{-1} .10 \mathrm{~km}^{3} \mathrm{y}^{-1}$ are left for evaporation losses from Lake Nasser (Haynes and Whittington,
1981). According to the agreement, the request of another riparian country(ies) has to be met equally from Egypt's and Sudan's share. All countries never recognized the treaty (Okidi, 1990; Nicol, 2003). It is important to note that, according to the 1959 bilateral agreement, the evaporation losses from man-made reservoirs in Sudan must be deducted from its share of the Nile waters. The first basin-wide dialogue initiative between countries has been initiated in 1997, with the Nile Basin Initiative (NBI). This organization aims at providing a framework to develop the river in a cooperative way, sharing socio-economic benefits and promoting regional security and peace. The NBI has successfully developed a number of so called shared-vision, and subsidiary action projects. However, the dialogue of the Nile riparians on a unified legal framework has not yet been completed. Five countries signed (May 2010), two countries boycotted, while the remaining two countries (Sudan and Egypt) strongly opposed (Nile Basin Initiative, May 2010a).

\subsection{Reservoirs and hydropower plants}

Currently, the Eastern Nile hydro-system consists of eleven major hydraulic infrastructures, listed in Table 1 and illustrated in Fig. 2.

Ethiopia - The first one is the Chara Chara weir that regulates the Lake Tana outflows to the Tis Abbay power 
Table 1. Major infrastructures: hydropower plants and reservoirs.

\begin{tabular}{|c|c|c|c|c|}
\hline $\begin{array}{l}\text { Name } \\
\text { (country) }\end{array}$ & River & $\begin{array}{r}\text { Live storage } \\
\left(\mathrm{hm}^{3}\right)\end{array}$ & $\begin{array}{r}\text { Capacity } \\
\text { (MW) }\end{array}$ & $\begin{array}{c}\text { Lateral irrigation } \\
\text { yes/no }\end{array}$ \\
\hline Tis Abbay I and II (ET) & Blue Nile & 0 (run-of-river) & 86 & no \\
\hline Tana-Beles link (ET) & Blue Nile & 0 (run-of-river) & 270 & no \\
\hline Karadobi* $^{*}(\mathrm{ET})$ & Blue Nile & 17000 & 1600 & no \\
\hline Beko-Abo* (ET) & Blue Nile & 20000 & 2100 & no \\
\hline Mandaya* (ET) & Blue Nile & 24600 & 1620 & no \\
\hline Border* (ET) & Blue Nile & 8500 & 1400 & no \\
\hline TK-5 (ET) & Atbara & 9200 & 300 & no \\
\hline Roseires (SU) & Blue Nile & 6900 & 275 & no \\
\hline Sennar (SU) & Blue Nile & 480 & 15 & yes \\
\hline Khashm El Girba (SU) & Atbara & 630 & 17 & yes \\
\hline Jebel Aulia (SU) & White Nile & 2800 & 30 & yes \\
\hline Merowe (SU) & Main Nile & 8300 & 1250 & no \\
\hline High Aswan Dam (EG) & Main Nile & 105900 & 2100 & no \\
\hline Old Aswan Dam (EG) & Main Nile & 0 (run-of-river) & 500 & no \\
\hline Esna (EG) & Main Nile & 0 (run-of-river) & 90 & no \\
\hline
\end{tabular}

* =planned, ET=Ethiopia, $\mathrm{SU}=$ Sudan, EG=Egypt.

Sources: ENTRO (2009), Block (2007); Whittington et al. (2005)

complex, located some $32 \mathrm{~km}$ downstream the Lake. Then, the Tana-Beles scheme (started operation in May 2010) consists of an artificial link between the Lake Tana and the Beles river to generate hydroelectricy and aims at irrigate around 150000 ha in the future. In the upper Ethiopian part of the Atbara sub-basin (Tekeze river in Ethiopia), the TK-5 dam is the largest Ethiopian hydraulic infrastructure. With an overyear storage capacity and an installed capacity of $300 \mathrm{MW}$, the TK-5 dam started to generate hydropower in 2009 and aims to produce around $30 \%$ of current total national electric production.

Sudan - Downstream, in Sudan, the main objective of the Roseires and Sennar dams is to provide seasonal regulation of the Nile waters to irrigate more than 1 million ha of crops distributed over 3 major schemes. Their associated hydropower stations supply Sudan in electricity but their production is relatively small given the low head available. Due to its physiographic characteristics, Sudan has only a few interesting sites to store water and suffers from a lack of overyear storage capacity to supply irrigation and reduce flood damage. To tackle this problem, the heightening of the Roseires dam started recently to bring its storage capacity up to $6.9 \mathrm{~km}^{3}$. The Atbara river (called Tekeze in Ethiopia) is dammed at Kashm El Girba where the installed capacity is relatively small and the reservoir is encountering reduction of storage capacity because of siltation. Located on the White Nile, near its confluence with the Blue Nile, the Jebel Aulia dam is presently operated to reduce pumping costs for the irrigated areas located around the reservoir. The Merowe dam, built close to the 4th cataract of the Nile, is the last significant infrastructure in Sudan. With an installed capacity of
$1250 \mathrm{MW}$, the Merowe hydropower plant will significantly increase the Sudanese production of hydroelectricity.

Egypt - In Egypt, the High Aswan Dam (HAD) is the largest infrastructure of the basin and it fully regulates the Nile waters downstream of the dam. Its over-year storage capacity and associated hydropower plant were designed to supply reliable irrigation water, meet increasing energy demand (around 9\% of current total national electric production), improve downstream navigation and to protect Egypt against flooding. Therefore, the HAD plays a crucial role in the Egyptian economy (Abu-Zeid and El-Shibini, 1997). Downstream HAD, the Old Aswan dam is operated as a runof-river plant; it slightly regulates the daily outflows from HAD and contributes to the production of electricity. The Esna run-of-river plant is the latest significant hydropower facility on the main stream of the Nile. Located in the Western Desert, the New Valley project aims at irrigate 250000 ha of crops by pumping water from the left bank of the Lake Nasser. The project is currently under construction but the pumping station and the major canals are already completed.

The major challenge for the Nile waters management is to control its seasonal and inter-annual variability. To date, as described above, only relatively small hydraulic infrastructures have been constructed in the Blue Nile catchment in Ethiopia, despite the huge hydropower potential offered by the topography of the country. Since the beginning of the 20th century, large-scale projects have been on the drawing board to develop the upper part of the basin which is currently a largely untapped resource (Whittington, 2004).

Under the umbrella of NBI, the Nile countries recently initiated a joint study to develop the Blue Nile in Ethiopia. The 
Table 2. Detailed description of the scenario.

\begin{tabular}{|c|c|c|c|c|c|}
\hline Scenario & & S1 & S2 & S3 & S4 \\
\hline \multirow[t]{3}{*}{ Infrastructures } & Ethiopia & $\begin{array}{l}\text { Lake Tana } \\
\text { Tis Abbay I and II } \\
\text { Tana-Beles link } \\
\text { TK-5 }\end{array}$ & $\begin{array}{l}\text { Lake Tana } \\
\text { Tis Abbay I and II } \\
\text { Tana-Beles link } \\
\text { TK-5 } \\
\text { Mandaya }\end{array}$ & $\begin{array}{l}\text { Lake Tana } \\
\text { Tis Abbay I and II } \\
\text { Tana-Beles link } \\
\text { TK-5 } \\
\text { Mandaya } \\
\text { Karadobi } \\
\text { Beko-Abo } \\
\text { Border }\end{array}$ & $\begin{array}{l}\text { Lake Tana } \\
\text { Tis Abbay I and II } \\
\text { Tana-Beles link } \\
\text { TK-5 } \\
\text { Mandaya } \\
\text { Karadobi } \\
\text { Beko-Abo } \\
\text { Border }\end{array}$ \\
\hline & Sudan & $\begin{array}{l}\text { Roseires } \\
\text { Sennar } \\
\text { Jebel Aulia } \\
\text { Kashm El Girba } \\
\text { Merowe }\end{array}$ & $\begin{array}{l}\text { Roseires } \\
\text { Sennar } \\
\text { Jebel Aulia } \\
\text { Kashm El Girba } \\
\text { Merowe }\end{array}$ & $\begin{array}{l}\text { Roseires } \\
\text { Sennar } \\
\text { Jebel Aulia } \\
\text { Kashm El Girba } \\
\text { Merowe }\end{array}$ & $\begin{array}{l}\text { Roseires } \\
\text { Sennar } \\
\text { Jebel Aulia } \\
\text { Kashm El Girba } \\
\text { Merowe }\end{array}$ \\
\hline & Egypt & $\begin{array}{l}\text { High Aswan } \\
\text { Old Aswan } \\
\text { Esna }\end{array}$ & $\begin{array}{l}\text { High Aswan } \\
\text { Old Aswan } \\
\text { Esna }\end{array}$ & $\begin{array}{l}\text { High Aswan } \\
\text { Old Aswan } \\
\text { Esna }\end{array}$ & $\begin{array}{l}\text { High Aswan } \\
\text { Old Aswan } \\
\text { Esna }\end{array}$ \\
\hline \multicolumn{2}{|c|}{ Installed capacity (MW) } & 4933 & 6933 & 11833 & 11833 \\
\hline Irrigated area & $\begin{array}{l}\text { Ethiopia } \\
\text { Sudan }\end{array}$ & $\begin{array}{l}\sim 0 \\
1.62\end{array}$ & $\begin{array}{l}0.02 \\
1.74\end{array}$ & $\begin{array}{l}0.15 \\
2.12\end{array}$ & $\begin{array}{l}0.15 \\
2.12\end{array}$ \\
\hline$\left(10^{6} \mathrm{ha}\right)$ & $\begin{array}{l}\text { Egypt } \\
\text { Total }\end{array}$ & $\begin{array}{l}5.68 \\
7.30\end{array}$ & $\begin{array}{l}5.71 \\
7.74\end{array}$ & $\begin{array}{l}5.90 \\
8.10\end{array}$ & $\begin{array}{l}5.90 \\
8.10\end{array}$ \\
\hline
\end{tabular}

objective of the proposed joint multipurpose projects are to minimize evaporation losses in the basin, increase flow reliability, generate cheap hydropower and enhance downstream energy production, alleviate downstream sedimentation and mitigate floods and droughts along the Nile and Blue Nile. The projects will boost the production of hydroelectricity and will probably have significant impacts on the management of the Nile waters. The existing and most likely projects to be implemented are listed in Table 1. Most of the information about infrastructures was obtained during field visits to the Eastern Nile Technical Regional Office (ENTRO, Addis Abeba, Ethiopia), which is the executive arm of NBI for projects related to the Eastern Nile River Basin, and the Ethiopian Ministry of Water Resources.

\subsection{Irrigated areas}

There are some potential irrigation developments directly in the Ethiopian part of the Blue Nile Basin, but they are relatively of limited size. Steep slopes and the deep incised valleys limit the possibilities for cheap irrigation in the Ethiopian Highlands. As a consequence, and except for very small areas, none of the proposed irrigation sites is taking water directly from the Blue Nile but rather around the Beles river. For Sudan and Ethiopia, crop water requirements were supplied by the Eastern Nile Technical Regional Office (ENTRO, Addis Abeba, Ethiopia). In Egypt, the annual water demand downstream the High Aswan Dam corresponds to the 1959 allotment of $55.5 \mathrm{~km}^{3}$. This volume of water is primarily used for irrigation purposes. The monthly distribution of the demand has been taken from Oven-Thompson et al. (1982) with the peaking water demand observed from May to August.

\subsection{Scenarios description}

Four scenarios were analyzed using the stochastic hydroeconomic model described in Sect. 2. Each scenario is characterized by an installed capacity and an irrigated area (Table 2). The first scenario (S1) corresponds to the current situation (base line scenario). The second scenario (S2) corresponds to the situation around 2025, with the most likely infrastructure to be built on the Blue Nile (Mandaya reservoir and hydropower plant) and a $10 \%$ increase of irrigation water demand in Ethiopia and Sudan. The third scenario (S3) is defined by the full development of the basin. The fourth scenario (S4) is imaginary: it is the same as the third one except that storage hydropower plants are replaced by run-of-river ones. In other words, S4 considers that there is no regulation capacity in Ethiopia (Table 2).

The comparison of the three first scenarios will evaluate the impacts of upstream development on the allocation decisions and reservoirs operating strategies (first objective) while the comparison of the third and fourth scenarios will assess the economic value of regulation (storage) in Ethiopia (second objective). The scenarios are detailed in Table 2. 


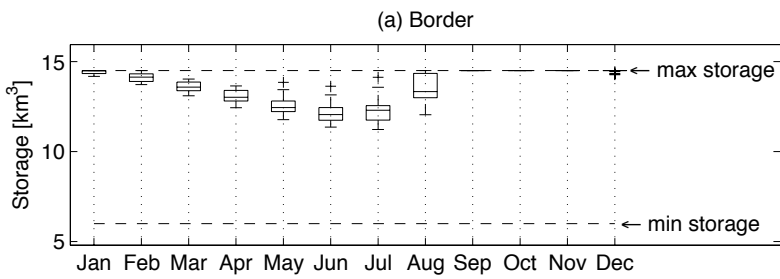

(b) Mendaya

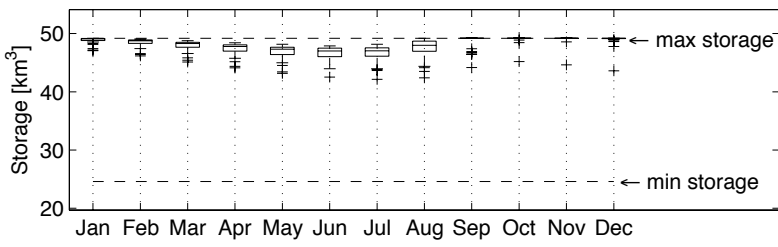

(c) Beko-Abo

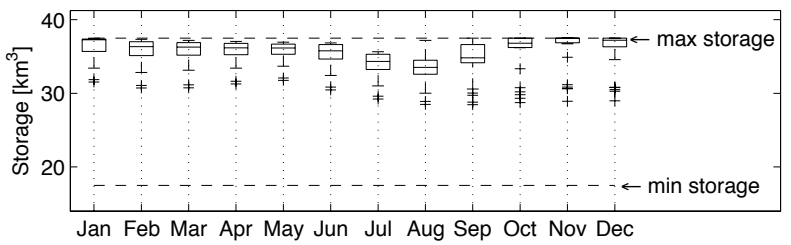

(d) Karadobi

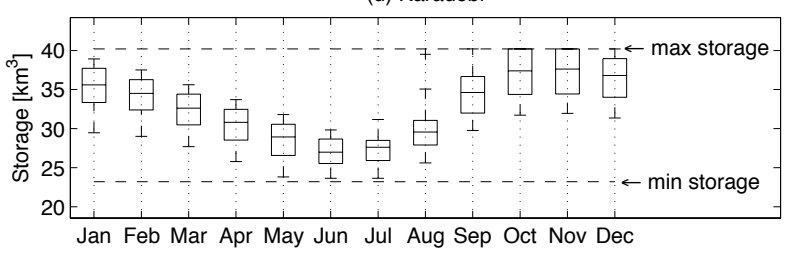

Fig. 3. Boxplots of the drawdown-refill cycles of the four multipurpose reservoirs in Ethiopia (Blue Nile) - scenario 3 (S3).

\subsection{Model parameters and assumptions}

Since the model solves the water allocation problem with a monthly time step with a planning horizon over one year, we are dealing with mid-to long-term hydro-scheduling. In that context and given the over-year storage capacity of the hydro-system, a 7 years ahead planning horizon is used ( $T=84$ month). Thirty backwards openings $(K=30)$ are setup and the forward simulation is carried out on 30 synthetic hydrological scenarios $(M=30)$. For each reservoir, a 47 years long historical record (from 1953 to 2000) of lateral inflows was available to estimate the parameters of the build-in multi-site periodic autoregressive hydrological model. We make the assumption that historical weather patterns are representative of possible future conditions.

The model described in Sect. 2 assumes the coordinated operation of all the infrastructures of the hydro-system. This implies, among other things, the existence of an institutional framework to ensure a basin-wide management of the system. In this study, we assume that the system is in steady state conditions and we do not consider the cost of building the infrastructures (considered as sunk cost). Block and

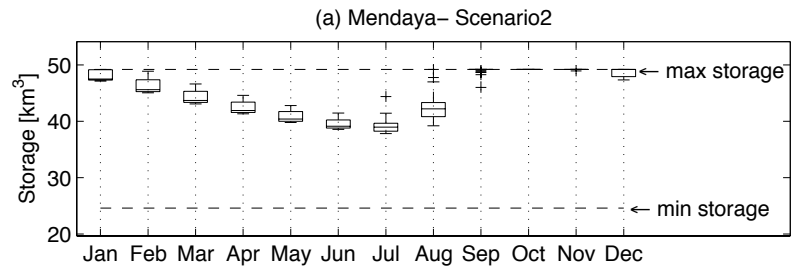

(b) Mendaya- Scenario3

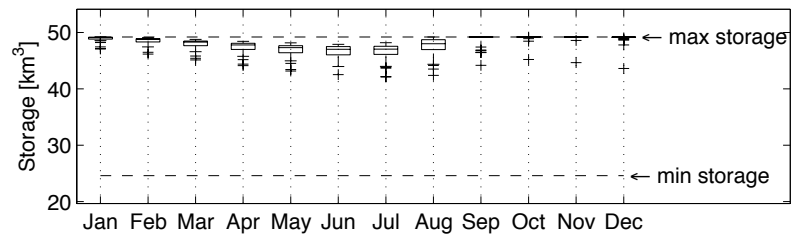

Fig. 4. Boxplots of the drawdown-refill cycles of the Mandaya reservoir in Ethiopia (Blue Nile) - S2 versus S3.

Strzepek (2010) analyzed the transient conditions associated with the period of filling the reservoirs, under climate change scenarios. Given the lack of accurate economic information about irrigated agriculture in the basin, we made the following assumptions. We consider flat demand curves for irrigation water withdrawals with a net return of $0.05 \mathrm{US} \$ / \mathrm{m}^{3}$, which is the same assumption as in Whittington et al. (2005). This value is consistent with international experience. For hydropower generation, we consider a seasonal SRMC averaging 80US $\$ / \mathrm{MWh}$ and identical throughout the countries of the region (Whittington et al., 2005).

\section{Results and analysis}

\subsection{Major reservoirs drawdown-refill cycles}

The drawdown-refill cycles of the cascade of planned infrastructures on the Blue Nile in Ethiopia (S3) are illustrated in Fig. 3. Karadobi, the first reservoir of the cascade, fully exploits its storage capacity: the pool elevation decreases during the dry season while the reservoir fills-up during the wet season. With an active storage capacity of $17 \mathrm{~km}^{3}$ and an average annual reservoir inflows estimated around $24.1 \mathrm{~km}^{3} \mathrm{y}^{-1}$, Karadobi regulates around $70 \%$ of its natural inflows and therefore controls the water availability for the rest of the cascade.

Downstream of Karadobi, the Beko-Abo reservoir controls the spills of Karadobi and the relatively small contribution of its sub-basin. As a consequence, the Beko-Abo reservoir exploits only the upper part of its storage capacity in order to maintain a high pool elevation that increases the productivity of its hydropower plant, which is the largest of the cascade (Table 1). The operation of the Mandaya reservoir differs depending on S2 or S3 (Fig. 4). In S2, Mandaya is the only large infrastructure on the Blue Nile in Ethiopia. The reservoir is therefore operated so as to control the large inflows 


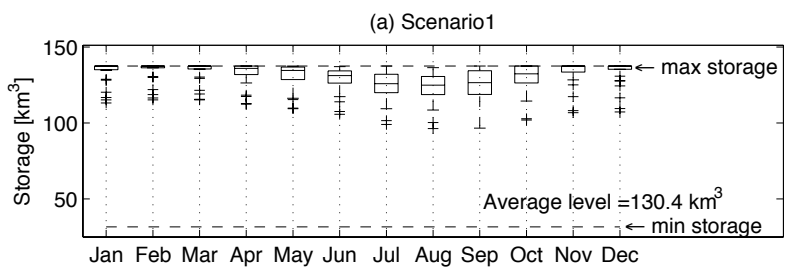

(b) Scenario2

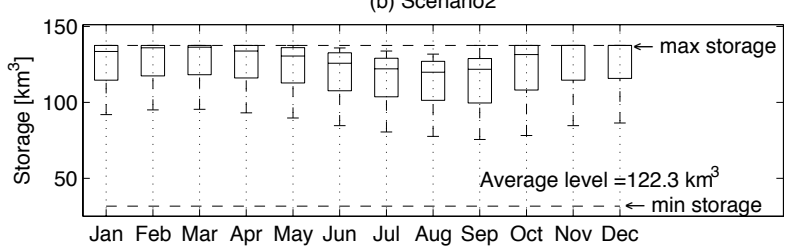

(c) Scenario3

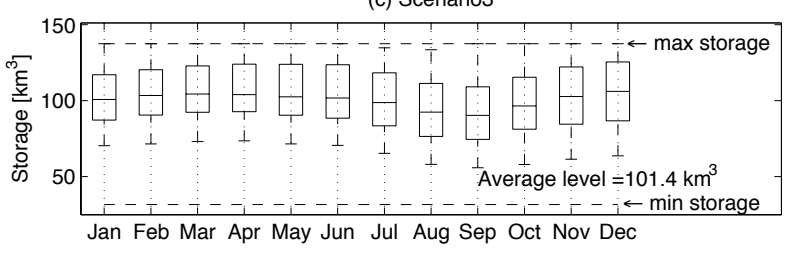

(d) Scenario4

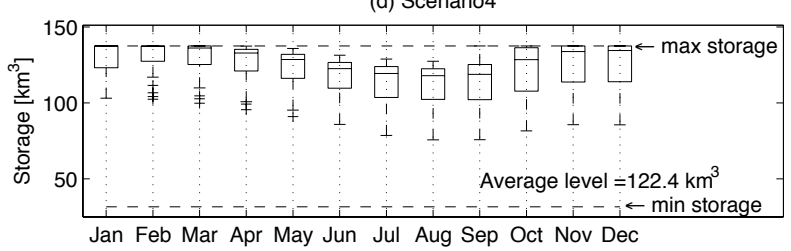

Fig. 5. Boxplots of the drawdown-refill cycles of the High Aswan Dam reservoir, for each scenario.

of its upstream sub-basins. On the other hand, the regulating role of the Mandaya reservoir decreases as other reservoirs are built upstream (S3), because the flow fluctuations are much smaller thanks to these reservoirs. Considering the full development scenario (S3), the increased upstream regulation allows Mandaya to be operated both at higher reservoir levels and with reduced spill. Downstream of the Mandaya reservoir and hydropower station, the discharge of the Blue Nile has already been regulated by the upstream reservoirs. The role of the Border dam, the latest before the border between Ethiopia and Sudan, is therefore to control the seasonal flow of its sub-basins. The reservoir exploits one third of its active storage capacity, which represents a trade-off between regulation capacity and reduced head on turbines.

Building new storage facilities in Ethiopia would impact the management strategies of downstream infrastructures. Figure 5 illustrates the drawdown-refill cycles of the High Aswan Dam reservoir, for the different scenarios. With any regulation capacity in the upper part of the Blue Nile Basin (S1 and S4), the water level in the reservoir decreases during the low flow season while the reservoir fills-up during the flood season. The drawdown-refill cycles vary seasonally according to the downstream water demand for irrigation pur- poses in the Nile delta. The lower pool elevation observed in $\mathrm{S} 4$ compared to $\mathrm{S} 1$ is explained by the higher water withdrawals for irrigation in Sudan and higher evaporation losses in Ethiopia. On the other hand, for the second and third scenario, the drawdown-refill cycles are reduced and the reservoir is operated at a much lower water level, especially in S3. The reason is that the flow has already been regulated by new Ethiopian infrastructures. Lower inflows and lower pool elevations will impact hydropower generation and evaporation losses in Egypt.

\subsection{Evaporation losses}

Box plots of annual evaporation losses from man-made reservoirs are displayed in Fig. 6. Currently, the Nile waters are regulated and stored in the High Aswan Dam reservoir, located at the border between Egypt and Sudan, and characterized by a very arid climate. It is therefore not surprising to observe evaporation losses ranging from 10.8 to $13.6 \mathrm{~km}^{3} \mathrm{y}^{-1}$. We can observe in Fig. 6 that the evaporation losses are reduced as more water is stored and regulated upstream in the basin (moving from S1 to S3). On average, the basin-wide water savings reach $2.5 \mathrm{~km}^{3} \mathrm{y}^{-1}$. This is due to the equatorial location of the Ethiopian reservoirs with lower temperatures and higher precipitations. Moreover, at full supply level (FSL), the cumulated impounded area of the Ethiopian reservoirs would represent $38 \%$ of the Lake Nasser's. Collectively, Ethiopian reservoirs represent $66 \%$ of Lake Nasser's potential in terms of active storage capacity and present therefore a great potential in terms of storage and flow regulation.

\subsection{Hydrological risk}

Figure 7 displays the statistical distributions of the annual flows at key locations in the river basin: (1) at the Sudanese and Ethiopian border, (2) at the Sudanese and Egyptian border, which represents the Lake Nasser inflows and (3) the High Aswan Dam releases. The three empirical cumulative distribution functions (CDF) available at each site give the non-exceedance probability of any given annual flow for the four scenarios.

As we will see later, the large storage capacities in Ethiopia would further increase irrigation withdrawals primarily in Sudan, where the productivities of irrigation districts can compete with that of downstream power stations (Merowe and HAD). Expanding crop irrigation in Ethiopia does not appear to be economically attractive as farmers are facing a coalition of downstream productive uses (a cascade of hydropower plants and irrigated agriculture in the delta) that prevent the expansion of consumptive uses upstream by attracting as much water as possible downstream in Sudan and Egypt.

The limited increase in irrigation withdrawals in Ethiopia and the fairly low evaporation losses from the proposed 

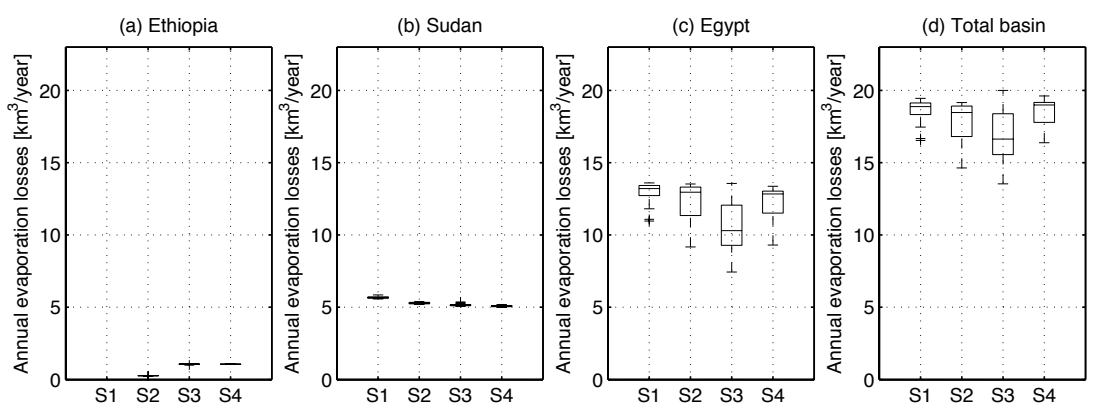

Fig. 6. Box-plots of annual evaporation losses, for the major countries of the basin and for each scenario.

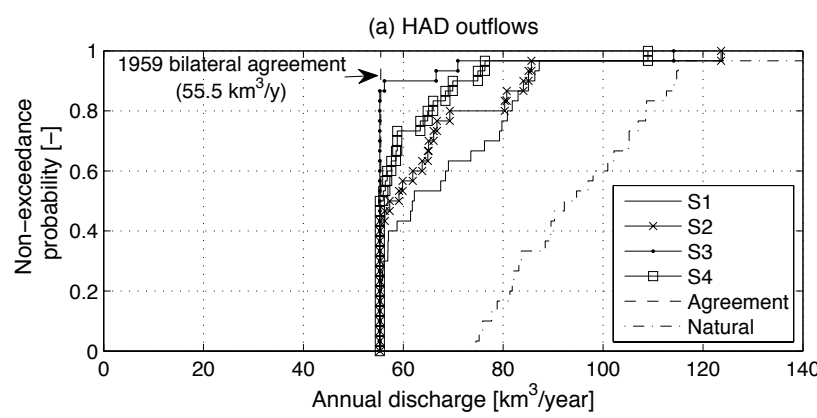

(b) HAD inflows

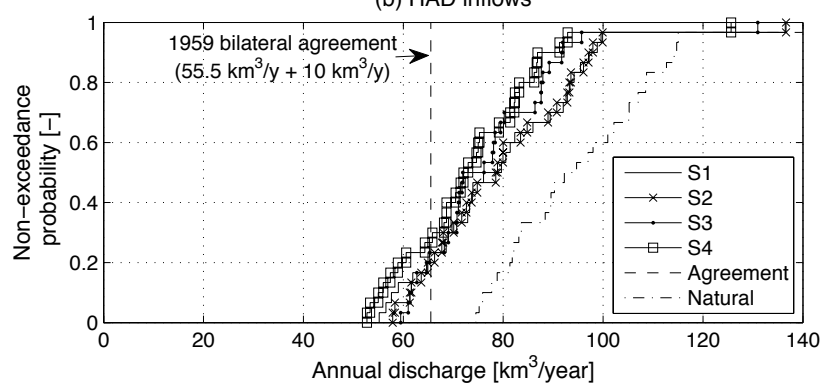

(c) Sudanese - Ethiopian border

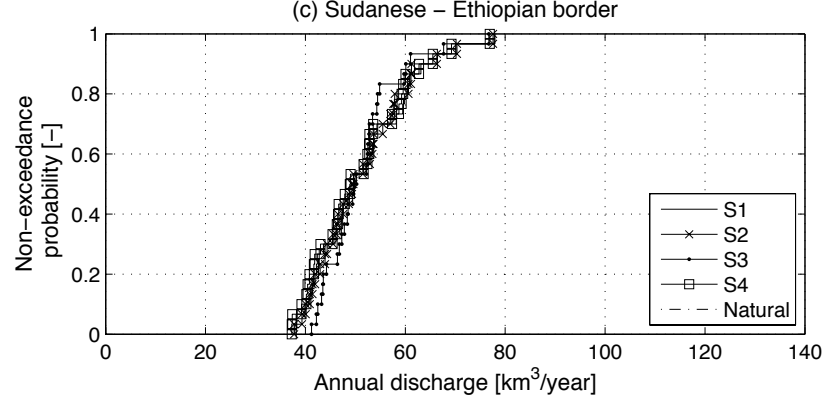

Fig. 7. Empirical cumulative distribution function (CDF) of the annual discharge at key locations. (a) High Aswan Dam outflows, (b) High Aswan Dam inflows and (c) Sudanese - Ethiopian border.

reservoirs are shown on Fig. 7c where we can see that the CDF of annual flows at the Ethiopian/Sudanese border for the second and third scenario is not significantly different from those of scenario 1. Fifty percent of the time, the annual discharge at the border will be greater than $49.5 \mathrm{~km}^{3} \mathrm{y}^{-1}$, whatever the scenario is.

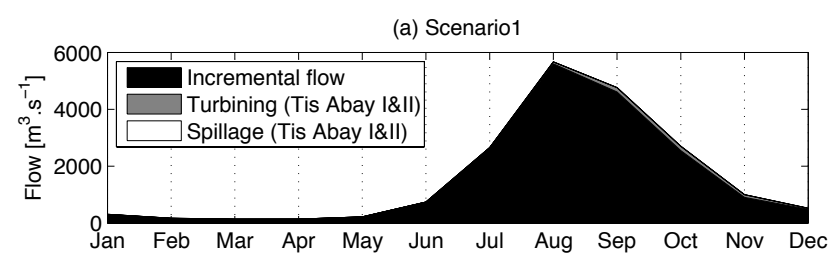

(b) Scenario2

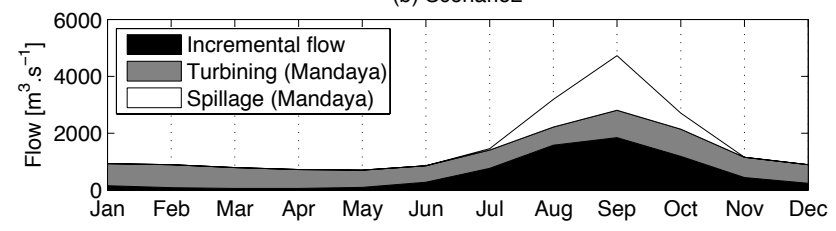

(c) Scenario3

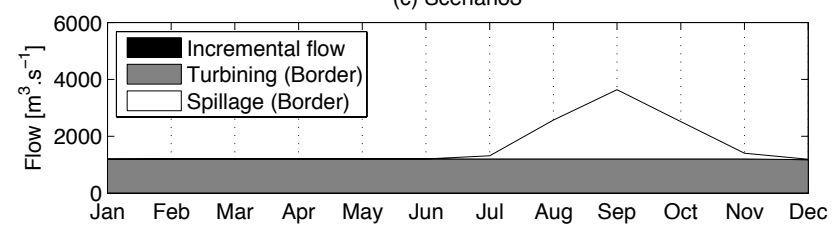

Fig. 8. Average monthly discharge downstream the cascade of Ethiopian reservoirs (Sudanese/Ethiopian border).

According to the 1959 bilateral agreement between Egypt and Sudan, the annual discharge into the Lake Nasser must be $65.5 \mathrm{~km}^{3} \mathrm{y}^{-1}\left(55.5 \mathrm{~km}^{3} \mathrm{y}^{-1}\right.$ for Egypt and $10 \mathrm{~km}^{3} \mathrm{y}^{-1}$ for evaporation losses at the Lake Nasser). We can see that the risk of not meeting the annual Egyptian allocation of $65 \mathrm{~km}^{3}$ (hydrological risk) will decrease from 23 to about $20 \%$ when the major storage and irrigation infrastructures will be operational (S2 and S3 - Fig. 7b). Finally, Fig. 7a illustrates that one should not downplay the role of HAD when the Ethiopian and Sudanese infrastructures will be operational; with its over-year storage capacity, HAD nullifies the crossborder hydrological risk by transferring water from wet to dry years, therefore preserving the reliability of supply to Egypt. In other words, Egypt still receives its annual allotment of $55.5 \mathrm{~km}^{3}$.

Building the proposed infrastructures in Ethiopia would have significant impacts on the flow regime of the Nile. Figure 8 illustrates, for the thee first scenarios, the average 
(a) Ethiopia

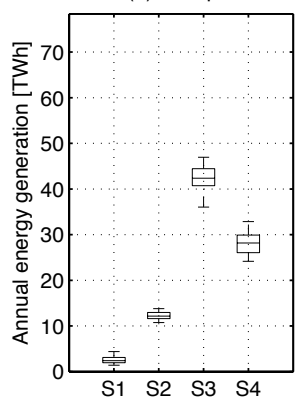

(b) Sudan

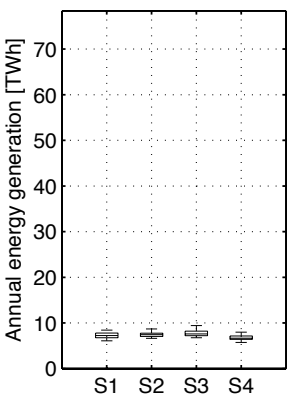

(c) Egypt

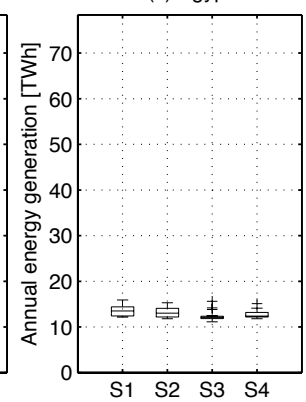

(d) Total basin

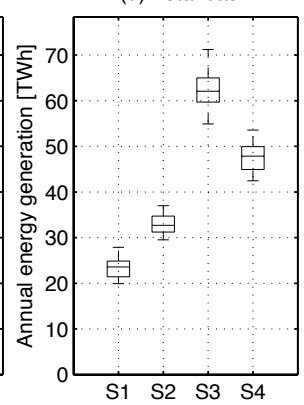

Fig. 9. Box-plots of annual hydropower generation, for the major countries of the basin and for each scenario.

Table 3. Benefits from upstream regulation (difference between $\mathrm{S} 3$ and $\mathrm{S} 4)$.

\begin{tabular}{lrrrr}
\hline Country & \multicolumn{2}{c}{$\begin{array}{l}\text { Hydropower } \\
\left(\mathrm{GWh} \mathrm{y}^{-1}\right)\end{array}$} & \multicolumn{2}{c}{$\begin{array}{c}\text { Irrigation } \\
\text { withdrawals } \\
\left(\mathrm{km}^{3} \mathrm{y}^{-1}\right)\end{array}$} \\
\hline Ethiopia & +14348 & $(+50.9 \%)$ & +0 & $(+0 \%)$ \\
Sudan & +956 & $(+14.3 \%)$ & +1.1 & $(+5.5 \%)$ \\
Egypt & -386 & $(-3.1 \%)$ & +0 & $(+0 \%)$ \\
\hline
\end{tabular}

monthly discharge of the Blue Nile at the border between Ethiopia and Sudan. The flow is decomposed into spillage and turbining from the immediately upstream power station and the natural inflow from the sub-basins. The first scenario is characterized by no regulation of the Blue Nile in Ethiopia. As more infrastructures are being implemented (S2 and S3, Fig. 8b, c, respectively), reservoirs have the ability to move water from the wet to the dry season. The flood peak observed in Fig. 8a (S1) from July to October is reduced by about one third and the discharge is much higher during the low flow season. Consequently, less frequent and reduced floodings, particularly in Sudan but also downstream would occur.

\subsection{Hydropower generation}

Boxplots of the annual hydropower generation, for each scenario and for each country are depicted in Fig. 9. As mentioned earlier, with both lower inflows and pool elevations, the production of hydroelectricity from HAD in Egypt would be reduced by $9 \%$ in S3 compared to S1. On the other hand, partial development of the basin (S2) would have no significant impact on Egyptian hydropower generation. Obviously, Ethiopia will be net beneficiary with an average increase of $469 \%$ and $1666 \%$ of annual energy generated from S2 and $\mathrm{S} 3$, respectively, and become therefore the largest hydroelectric producer of the Eastern Nile Basin. Sudan would also benefit from the upstream infrastructures: reduced spillage makes more water available for hydropower generation.

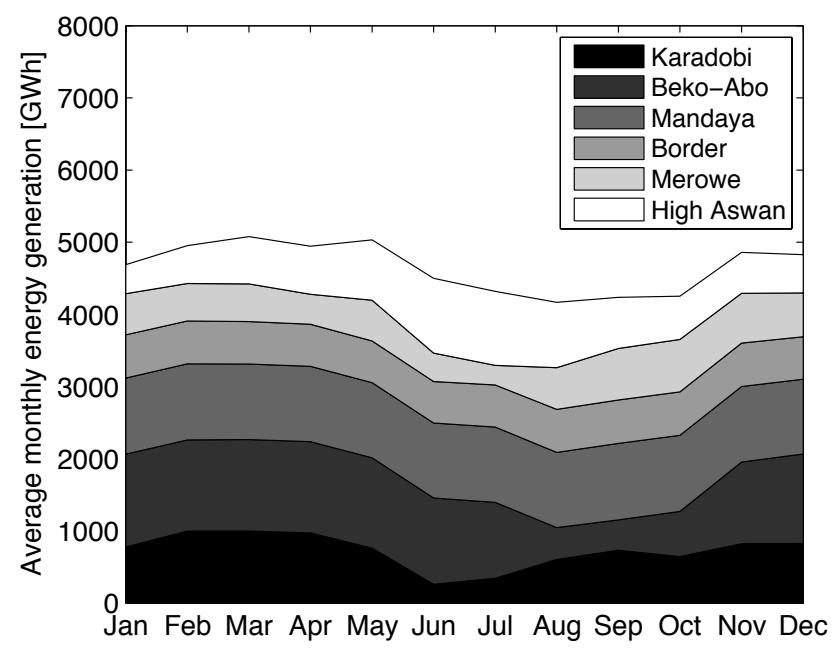

Fig. 10. Stacked monthly average energy generated by the major power plants throughout the basin - scenario 3 .

Figure 10 illustrates, for the full development scenario (S3), the monthly average energy generated by the major hydropower plants throughout the basin. The temporal distribution is coherent with the hydrology and the seasonality of reservoirs releases. On the other hand, the wet season is characterized by lower energy valuse and the reservoirs operators are consequently keen to store water to release it during the next wet season, when it becomes more valuable.

By analyzing the difference between S3 and S4, we can assess the added value of the regulation capacity of the proposed reservoirs located in Ethiopia. We can see on Fig. 9 that, moving from S1 to S3 would increase the hydropower generation in Ethiopia by $+40 \mathrm{TWh}(+1666 \%)$, amongst which 14.3 TWh due to storage (Table 3). At the basinscale, the annual production of hydroelectricity is boosted by $+38.5 \mathrm{TWh}(+163 \%)$ amongst which $14.2 \mathrm{TWh}$ due to the regulation capacity of Ethiopian reservoirs. Positive impacts are also observed for Sudan where less spillage occurs. On the other hand, less power is generated in Egypt. Figure 11 analyzes the temporal distribution of the benefits from upstream regulation on hydropower generation, by 


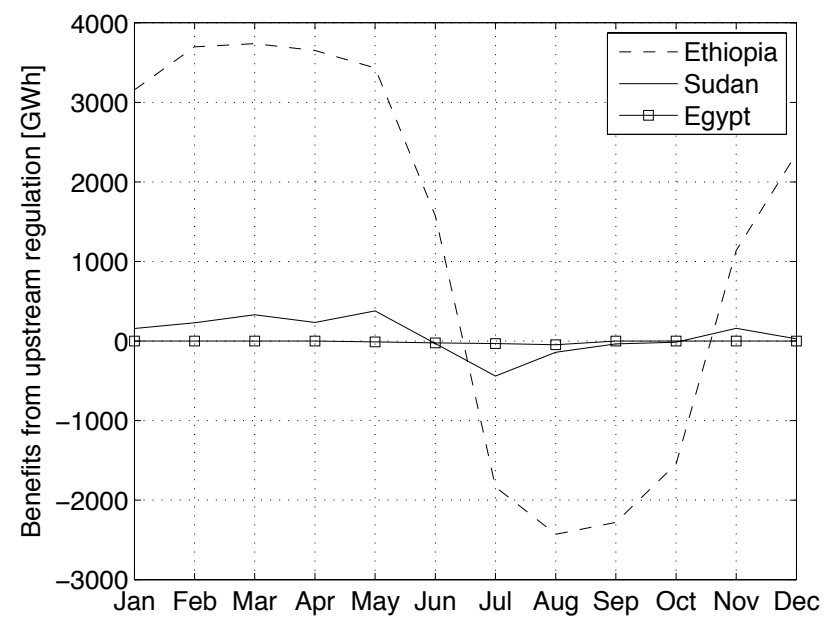

Fig. 11. Temporal repartition of benefits (hydropower) from upstream regulation.

illustrating the monthly difference between S3 and S4. The figure reveals that, during the low flow season, Ethiopia and Sudan take advantage from the regulation. The main beneficiary is obviously Ethiopia. We can also observe that the production of hydroelectricity is differed from the wet season to the dry season, when the SRMC of the hydrothermal electrical system to which hydropower plants contribute are increasing.

\subsection{Irrigation}

We saw on Fig. 7b that the development of the upstream part of the basin (S2 and S3) induces a reduction of the flow to Egypt: the annual volume of water crossing the border between Sudan and Egypt would be lower than $65.5 \mathrm{~km}^{3} 23 \%$ or $20 \%$ of the time for S2 and S3, respectively. That reduction essentially comes from increased irrigation withdrawals in Sudan but, thanks to the over-year storage capacity of Aswan, that reduction is not accompanied by a reduction in the reliability of supply; Egypt still receives its annual allotment of $55.5 \mathrm{~km}^{3} \mathrm{y}^{-1}$ with no risk of failure. The role of the High Aswan Dam should therefore not be downpayed, especially when dry or wet years occur. In the third scenario, nearly all potential irrigated areas in Sudan and in Egypt are effectively irrigated. Irrigated agriculture in Sudan therefore benefits from upstream storage in Ethiopia since the $\mathrm{Su}$ danese annual withdrawals are lower in scenarios 1,2 and 4. Those allocation decisions illustrate that once water has passed through the Ethiopian hydropower plants, irrigated agriculture starts competing with hydropower generation and irrigation withdrawals become more economically sound.

Table 3 illustrates the benefits of storage in Ethiopia, on the irrigated agriculture sector. The regulation capacity of the reservoirs located in Ethiopia would increase irrigation water withdrawals by $5.5 \%$ in Sudan. No significant impacts is observed for Egypt and Ethiopia.

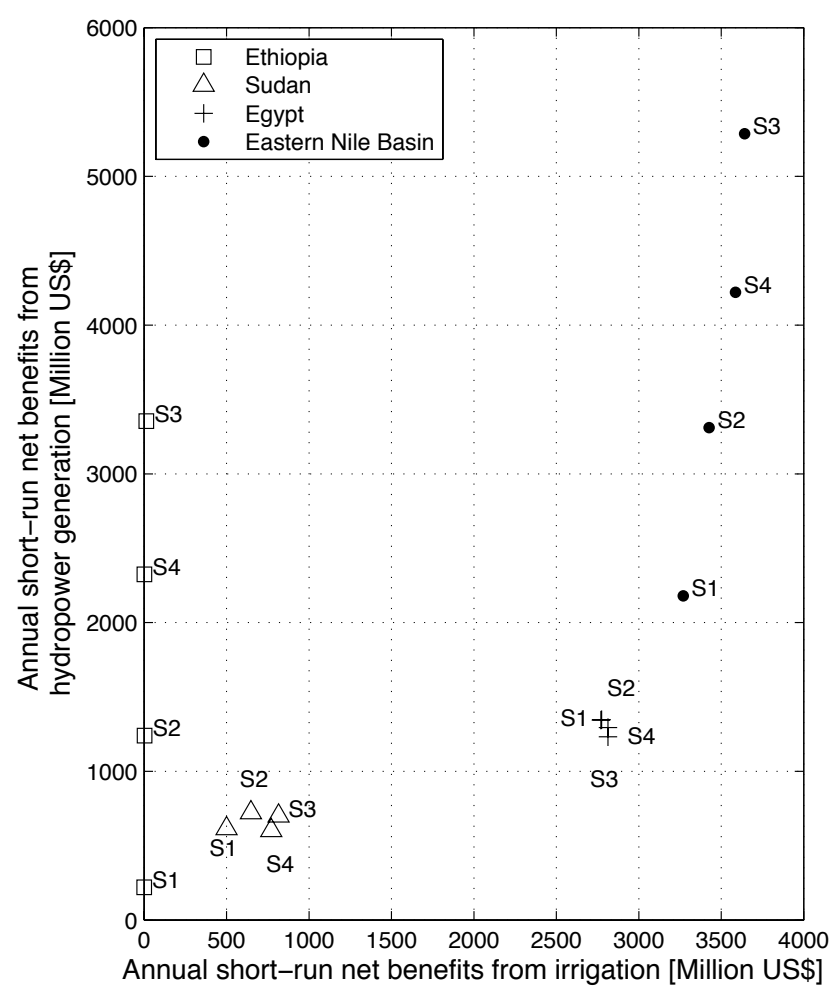

Fig. 12. Average annual short-run net benefits from hydropower generation and irrigation.

\subsection{Impacts of sediments}

Soil erosion of the intensively farmed highlands in the Ethiopian Plateau is a major source of sedimentation in downstream reservoirs. The annual sediment load of the basin is estimated around $140 \mathrm{Mt} / \mathrm{y}$ at Roseires (Norplan, Norconsult \& Lahmeyer International, 2006). However, construction of the four mega dams on the Blue Nile within Ethiopia will significantly trap sediment which currently discharges down the Blue Nile in Sudan particularly in the flood season months of July to September. Secondly, the regulated flow will substantially reduce the flood plain area along the rivers in Sudan.

\subsection{Short-run net benefits}

Figure 12 reveals a huge increase in basin-wide benefits due to the new hydropower stations in Ethiopia and irrigated areas in Sudan. On average, these infrastructures would increase annual basin-wide benefits by 3.48 billion US\$ $(+63.8 \%)$ or 1.29 billion US\$ $(+23.7 \%)$ for S3 or S2 respectively. Unsurprisingly, the largest increase is to be observed in Ethiopia ( +3.18 billion US\$/y for S3 and +1.04 billion US\$/y for S2) and then in $\mathrm{Su}-$ dan $(+0.27$ billion US\$ for $\mathrm{S} 2$ and +0.43 billion US\$ for S3). However, upstream developments would cost Egypt 
0.0 billion US\$/y (S3) essentially due to the reduction in hydropower generation from HAD.

Note that the development of run-of-river in lieu of storage hydropower plants in Ethiopia (S4) would also yield significant basin-wide benefits. The comparison of basin-wide benefits in S3 and S4 gives how much economic benefits can be obtained from storing water in Ethiopia. The storage services in Ethiopia would, on average, yield an annual extra value of 1.12 billion US\$/y, which corresponds to $14.4 \%$ of the basin-wide benefits.

\section{Conclusions}

Four development scenarios for the Eastern Nile River Basin were analyzed using a stochastic hydro-economic model. The objective was (1) to evaluate the impacts of upstream development in the Blue Nile Basin on the allocation decisions and reservoirs operating strategies and (2) to assess the economic value of regulation (reservoirs) in Ethiopia. The analysis focused on two economic sectors: irrigation and hydropower generation.

The analysis reveals that building new large infrastructures in the upper part of the basin would have significant impacts on the operating strategies of the reservoirs: should the operation of the reservoirs be coordinated, the flood peak observed in the Blue Nile would be reduced while the low flows would be augmented. The main beneficiaries are hydropower in Ethiopia and irrigation in Sudan. Moreover, upstream storage in Ethiopia (and their regulation capacity) will generate positive externalities in Ethiopia and Sudan. In Ethiopia, the production of hydroelectricity is boosted by $40 \mathrm{TWh}(+1666 \%)$, amongst which $14.3 \mathrm{TWh}$ due to the regulation capacity of Karadobi, Beko-Abo, Mandaya and Border. In Sudan, the regulation capacity would increase irrigation water withdrawals by $5.5 \%$. Coordinated operation of the reservoirs would also enable an average annual saving of at least 2.5 billion $\mathrm{m}^{3}$ through reduced evaporation losses from the High Aswan Dam. The High Aswan Dam inflows would be reduced and the reservoir would be operated at lower pool elevation but it will still reduce the hydrological risk exposure of Egypt: the reliability of supply to Egypt (according to the 1959 bilateral agreement) would not be affected. Such hydro-economic analysis helps Eastern Nile riparians on their endeavors for coordinated managment of the basin.

\section{References}

Abu-Zeid, M. A. and El-Shibini, F. Z.: Egypt's High Aswan Dam, Int. J. Water Resour. D., 13, 209-217, 1997.

Block, P.: Integrated management of the Blue Nile Basin in Ethiopia: hydropower and irrigation modeling, International Food Policy Research Institute, Washington, DC, Discussion Paper 00700, 2007.
Block, P. and Strzepek, K.: Economic analysis of large-scale upstream river basin development on the Blue Nile in Ethiopia considering transient conditions, climate variability, and climate change, J. Water Res. Pl.-ASCE, 136, 156-166, 2010.

Georgakakos, A.: Decision support systems for integrated water resources management with an application to the Nile Basin, in: Topics on System Analysis and Integrated Water Resources Management, edited by: Castelletti, A. and SonciniSessa, R., Elsevier, 2006.

Goor, Q., Kelman, R., and Tilmant, A.: Optimal multipurposemultireservoir operation model with variable productivity of hydropower plants, J. Water Res. Pl.-ASCE, accepted, 2010.

Guariso, G. and Whittington, D.: Implications of ethiopian water development for Egypt and Sudan, Int. J. Water Resour. D., 3 , 105-114, 1987.

Harou, J. J., Pulido-Velazquez, M., Rosenberg, D. E., MedellinAzuara, J., Lund, J. R., and Howitt, R. E.: Hydro-economic models: concepts, design, applications, and future prospects, J. Hydrol., 375, 627-643, 2009.

Haynes, K. E. and Whittington, D.: International management of the Nile. Stage three?, Geogr. Rev., 71, 17-32, 1981.

Huang, W.-C., Harboe, R., and Bogardi, J. J.: Testing stochastic dynamic programming models conditioned on observed or forecasted inflows, J. Water Res., Pl.-ASCE, 117, 28-36, 1991.

Labadie, J.: Optimal operation of multireservoir system: state-ofthe-art review, J. Water Res., Pl.-ASCE, 130, 93-111, 2004.

Nicol, A.: The Nile: moving beyond cooperation, UNESCO-IHP Technical Documents in Hydrodology, UNESCO, Paris, France, PC-CP series nr. 16, 33 pp., 2003.

Nile Basin Initiative: Eastern Nile Subsidiary Action Program (ENSAP) website, http://ensap.nilebasin.org (last access: May 2010), 2010a.

Nile Basin Initiative: Nile Basin Initiative website, http://www. nilebasin.org (last access: May 2010), 2010b.

Norplan, Norconsult \& Lahmeyer International. 2006. Karadobi Multipurpose Projet pre-feasibility study (Final Report) - Volume 5, Initial Environmental Assessment. The Federal Democratic Republic of Ethiopia, Ministry of Water Resources.

Okidi, C.: History of the Nile and Lake Victoria Basins through treaties, in: The Nile: Resource Evaluation, Resource Management, Hydropolitics and Legal Issues, edited by: Howell, P. P., Press Syndicate of the University of Cambridge, Cambridge, UK, 1990.

Oven-Thompson, K., Alercon, L., and Marks, D. H.: Agricultural vs. hydropower tradeoffs in the operation of the High Aswan Dam, Water Resour. Res., 18, 1605-1613, 1982.

Pereira, M. V. F. and Pinto, L. M. V. G.: Stochastic optimization of a multireservoir hydroelectric system: a decomposition approach, Water Resour. Res., 21, 779-792, 1985.

Powell, W. B.: Approximate Dynamic Programming: Solving the Curses of Dimensionality, John Wiley \& Sons, Inc., ISBN13: 9780470171554, 2007.

Ringler, C., von Braun, J., and Rosegrant, M. W.: Water policy analysis for the Mekong River Basin, Water Int., 29, 30-42, 2004.

Tejada-Guibert, J. A., Johnson, S. A., and Stedinger, J. R.: The value of hydrologic information in stochastic dynamic programming models of a multireservoir system, Water Resour. Res., 31, 2571-2579, 1995.

Tilmant, A. and Kelman, R.: A stochastic approach for an- 
alyzing trade-offs and risks associated with large-scale water resources systems, Water Resour. Res., 43, W06425, doi:10.1029/2006WR005094, 2007.

Tilmant, A., Goor, Q., and Pinte, D.: Assessing marginal water values in multipurpose multireservoir systems via stochastic programming, Water Resour. Res., 44, W12431, doi:10.1029/2008WR007024, 2008.

Tilmant, A., Goor, Q., and Pinte, D.: Agricultural-to-hydropower water transfers: sharing water and benefits in hydropowerirrigation systems, Hydrol. Earth Syst. Sci., 13, 1091-1101, doi:10.5194/hess-13-1091-2009, 2009.

Ward, F. A. and Michelsen, A.: The economic value of water in agriculture: concepts and policy applications, Water Policy, 4, 423-446, 2002.
Ward, F. A., Booker, J. F., and Michelsen, A. M.: Integrated economic, hydrologic, and institutional analysis of policy responses to mitigate drought impacts in Rio Grande Basin, J. Water Res. Pl.-ASCE, 132, 488-502, 2006.

Whittington, D.: Visions of Nile Basin development, Water Policy, 6, 1-24, 2004.

Whittington, D., Wu, X., and Sadoff, C.: Water resources management in the Nile Basin: the economic value of cooperation, Water Policy, 7, 227-252, 2005.

Wu, X. and Whittington, D.: Incentive compatibility and conflict resolution in international river basins: a case study of the Nile Basin, Water Resour. Res., 42, doi:10.1029/2005WR004238, 2006. 